ARTIGO

\title{
Rendimento escolar: um estudo comparativo entre alunos da área urbana e da área rural em uma escola pública do Piauí
}

Suzana Gomes Lopes a Isabel Matilde de Carvalho Xavier ${ }^{b}$ Alexandre Leite dos Santos Silva ${ }^{c}$

\section{Resumo}

O objetivo principal deste estudo foi comparar o rendimento escolar entre alunos do $6^{\circ}$ ano que residem nas áreas rural e urbana de uma escola pública do Piauí. Além disso, investigaram-se as causas socioeconômicas e escolares que influenciam tal rendimento, segundo os professores e os alunos. Os dados de rendimento foram obtidos mediante registros escolares, e os fatores influenciadores de rendimento foram investigados por meio de questionários e de entrevistas. Os registros escolares apontaram que os alunos que residem em área rural possuem um menor rendimento em comparação àqueles que moram na área urbana. Esta variação estaria ligada a aspectos sociais e escolares em diferentes níveis: de aluno, de turma e de escola.

Palavras-chave: Avaliação Escolar. Rural-urbano. Fatores Influenciadores.

\section{Introdução}

A Educação é estabelecida como direito social na Constituição Federal, que ainda afirma que o ensino deve possuir um padrão de qualidade (BRASIL, 1988). Tais direitos são reafirmados na Lei de Diretrizes e Bases da Educação Nacional, que prevê um "processo nacional de avaliação do rendimento escolar [...] objetivando a definição de prioridades e a melhoria da qualidade do ensino" (BRASIL, 1996, p. 10). Assim, pode-se inferir que os processos avaliativos são

\footnotetext{
a Universidade Federal do Piauí, Picos, Pl, Brasil.

b Universidade Federal do Piauí, Picos, Pl, Brasil.

c Universidade Federal do Piauí, Picos, PI, Brasil.
} 
utilizados como ferramentas para análise da qualidade de ensino. Isso ocorre não somente em escala e em nível nacional, mas em cada uma das instituições escolares que podem ter formas próprias de medir o rendimento escolar estabelecidas em seus Projetos Político-Pedagógicos (PPP).

O rendimento deve refletir "tanto a aquisição de conhecimentos e informações decorrentes dos conteúdos curriculares quanto as habilidades, interesses, atitudes, hábitos de estudo e ajustamento pessoal e social" (HAYDT, 1997, p. 10). De acordo com Silva (2011):

O rendimento escolar pode ser definido como as modificações no indivíduo proporcionadas pela aprendizagem no contexto escolar e que são mensuradas e categorizadas em índices (notas ou conceitos) que apontam critérios de aproveitamento da situação de ensino e aprendizagem de conteúdos (bom rendimento) ou o não aproveitamento do ensino e aprendizagem insatisfatória (fraco rendimento) (p. 23).

Dessa forma, mais que notas e conceitos expressos pelo professor, o rendimento escolar, realizado à base de um sistema de valores, critérios e indicadores, pode referir-se a uma mudança de comportamento e, consequentemente, à aprendizagem de um indivíduo ou de uma coletividade (MASCARENHAS, 2004; PARREIRA; SILVA, 2015).

A avaliação do rendimento escolar possui dois objetivos principais: identificar as dificuldades de aprendizagem dos alunos para ajudá-los a superá-las; e avaliar a eficácia do ensino, sendo considerado um parâmetro de análise para o trabalho desenvolvido em sala de aula e na escola, refletindo assim a qualidade do ensino (HAYDT, 1997).

Para traçar ações necessárias para a melhoria da qualidade do ensino não basta avaliar o rendimento como um ponto isolado: deve-se conhecer o contexto escolar e os fatores socioeconômicos que influenciam tais resultados, porém, notas e provas não fornecem tais informações (AMÉRICO; LACRUZ, 2017; COSTA, 2005; FARIA; GUIMARÃES, 2015). Nesse sentido, na literatura acadêmica, existem relatos de vários fatores internos e externos à escola que podem afetar o rendimento dos alunos nas avaliações (OSTI; MARTINELLI, 2014; VILELA-RIBEIRO; BENITE, 2015). "Entre os fatores que impactam o desempenho cognitivo dos alunos da Educação Básica destacam-se a sua 
família, as estruturas da sociedade e a escola onde ele estuda" (SOARES; ANDRADE, 2006, p. 107).

Por isso, esta pesquisa partiu do interesse em saber quais fatores influenciam o rendimento escolar de alunos que moram em localidades rurais ${ }^{1}$, atendidos em uma escola localizada na área urbana de um município piauiense. Tal interesse, por sua vez, decorreu de relatos feitos, aos pesquisadores, por professores e coordenadores pedagógicos, que atuavam na instituição, afirmando que os alunos residentes na área rural chegavam à escola com uma defasagem de aprendizagem em relação aos que moravam na área urbana.

Por isso, o objetivo principal deste estudo foi comparar o rendimento escolar entre alunos que residem na área rural e na área urbana de uma escola pública de um município piauiense. Além disso, este trabalho buscou investigar os fatores influenciadores de rendimento destes alunos que moram na área rural e estudam em uma escola localizada na área urbana.

\subsection{Fatores influenciadores do rendimento escolar}

$\mathrm{Na}$ literatura, existem relatos de vários fatores, internos e externos à escola, que podem afetar o rendimento dos alunos nas avaliações. Nesse tipo de estudo, que remonta à década de 1960, destaca-se, dentre outros, o trabalho de Coleman, o qual indica que o contexto social e econômico, inclusive a família, influencia os resultados escolares (COLEMAN, 2008; COLEMAN et al., 1966). Por isso, classes ou estratos sociais são abordados nas pesquisas educacionais sobre rendimento escolar (ALVES; SOARES; XAVIER, 2014).

Esses fatores podem ser organizados em níveis hierárquicos. Nesse sentido, Palermo, Silva e Novellino (2014) organizaram tais fatores em três níveis distintos: (i) ao nível do aluno, compreendendo aspectos pessoais e familiares como características sociodemográficas e capital socioeconômico e cultural familiar; (ii) ao nível de turma, relacionado aos aspectos da sala de aula, como características do professor, efeito dos pares, e estilos e práticas pedagógicas; e (iii) ao nível da escola, englobando fatores relativos à instituição de ensino, como violência, políticas ou práticas escolares.

\footnotetext{
Tal classificação de área urbana e de área rural segue o estabelecido pelo Instituto Brasileiro de Geografia e Estatística - IBGE (2011). Entende-se que os domicílios de situação urbana são aqueles localizados nas áreas urbanas, que são as áreas internas ao perímetro urbano de uma cidade ou vila, definido por lei municipal. Os domicílios de situação rural são aqueles localizados nas áreas rurais, definidas como áreas externas aos perímetros urbanos, inclusive nos aglomerados rurais de extensão urbana, povoados, núcleos e outros aglomerados.
} 
Considerando tais fatores e níveis, e a realidade do aluno da área rural, questionou-se nesta pesquisa se o rendimento desses alunos seria diferente daqueles que moram na área urbana, mesmo que ambos façam parte do corpo discente da mesma escola. Tal indagação parte da reflexão sobre "as díspares socioeconômicas que permeiam os processos de aprendizagem dos sujeitos do campo e articulam-se com as desigualdades da renda auferida pelo núcleo familiar, com desigualdades de acesso, de formação e de infraestrutura presentes no campo brasileiro" (OLIVEIRA; MONTENEGRO, 2010, p. 47).

\subsection{Rural e urbano em contexto: a relação da situação de domicílio e do rendimento escolar}

A pesquisa foi desenvolvida no segundo semestre do ano de 2017, com três turmas de alunos do sexto ano e professores da escola nomeada como EMM ${ }^{2}$. Esta escola é a única que oferta os anos finais do Ensino Fundamental na sede de um município do estado do Piauí. Assim, devido a sua localização, a EMM é classificada como uma escola urbana (FUNDAÇÃO LEMANN, 2016). Porém, a instituição agrega um corpo misto de alunos: alguns residem na área urbana e outros na área rural, sendo a maioria desta última, oriundos de diversas comunidades. Essa situação também foi encontrada por outros pesquisadores, embora em outros contextos, como Bacha et al. (2006) e Rodrigues (2017).

Um artigo publicado por Bacha et al. (2006) mostrou a análise e a comparação das notas escolares de 641 alunos do Ensino Fundamental residentes na área urbana e na área rural de escolas públicas urbanas do município de Terenos, estado do Mato Grosso do Sul. As notas analisadas, dos dois primeiros bimestres de 2005, eram referentes às disciplinas de Língua Portuguesa, Matemática, Ciências, Geografia, História, Educação Artística e Educação Física. Esse estudo constatou que o rendimento dos alunos residentes na área urbana era ligeiramente maior do que os que residiam na área rural, nos anos finais do Ensino Fundamental.

Rodrigues (2017), em sua dissertação de Mestrado pela Universidade Federal do Ceará, fez um estudo comparativo do rendimento de estudantes do último ano do Ensino Médio, através de microdados do Exame Nacional do Ensino Médio (Enem) de 2014. Além das variáveis contextuais, a pesquisadora estudou os rendimentos nas áreas de Ciências da Natureza, Ciências Humanas, Linguagens e Códigos e Matemática. Ela comparou o rendimento de alunos que residiam no meio rural com

\footnotetext{
Por motivos éticos, o nome da escola em que foi desenvolvida a pesquisa foi suprimido deste artigo. Para tal, a escola é referenciada como EMM.
} 
os que residiam no meio urbano, embora fossem de escolas similares, e constatou que os residentes na área urbana tinham um desempenho maior que os residentes na área rural. As desigualdades foram relacionadas com diversas características das escolas, dos professores, dos alunos e das famílias, como, por exemplo, os insumos pedagógicos das escolas, a formação dos professores, a motivação dos alunos para o estudo e o perfil socioeconômico dos pais.

Como os trabalhos supramencionados, este também faz uma abordagem comparativa do rendimento entre alunos residentes nas áreas urbana e rural de uma mesma escola, buscando os fatores influenciadores dessa desigualdade. Como Bacha et al. (2006), o estudo foi voltado para o Ensino Fundamental. Da mesma forma que Rodrigues (2017), foi um estudo realizado na região Nordeste. Porém, contribui problematizando dentro da realidade do semiárido piauiense, que detém suas peculiaridades naturais, socioeconômicas e culturais em relação ao restante do país. Além disso, este estudo optou por uma metodologia que ampliasse os tipos de base de dados e de instrumentos de coleta.

\section{Metodologia}

Para atingir os objetivos, este estudo foi desenvolvido por meio de uma abordagem mista, na qual se realizou um levantamento de dados quantitativos e a análise de cunho qualitativo. Os métodos mistos combinam os métodos predeterminados das pesquisas quantitativas com métodos emergentes das qualitativas, assim como questões abertas e fechadas, com formas múltiplas de dados contemplando todas as possibilidades, incluindo análises estatísticas e análises textuais. Nesse caso, os instrumentos de coleta de dados podem ser ampliados com observações abertas, ou mesmo, os dados censitários podem ser seguidos por entrevistas exploratórias com maior profundidade (DAL-FARRA; LOPES, 2013). Nessa perspectiva, os dados desta pesquisa foram coletados através de: (1) registros escolares, como diários, relatórios de acompanhamento do rendimento escolar e da localidade dos alunos; (2) questionários, com questões abertas e fechadas; e (3) entrevistas semiestruturadas.

Foram analisados os registros escolares para possibilitar a construção de um perfil e do rendimento escolar de 88 alunos. Tais dados foram coletados a partir de diários, relatórios de acompanhamento do rendimento escolar e da localidade dos alunos, e foram consideradas todas as avaliações realizadas no ano letivo de 2017. As disciplinas analisadas, quanto ao rendimento escolar, foram consideradas as disciplinas Português, Matemática e Ciências, pois estas são as áreas do conhecimento recorrentes em avaliações de larga escala em nível nacional e internacional, como, por exemplo, a Avaliação Nacional 
do Rendimento Escolar (Anresc, também conhecida como Prova Brasil), e o Programme for International Student Assessment (Pisa).

Além dos registros escolares, questionários foram aplicados no ano letivo de 2017 aos alunos do sexto ano, pelo fato de ser um ano de transição, em que os alunos da área rural migram para a escola na área urbana ${ }^{3}$. Foram recolhidos 18 questionários respondidos, que subsidiaram o levantamento de aspectos sociais e escolares que poderiam afetar o rendimento, como o uso de transporte escolar, acompanhamento dos pais e o estudo em classes multisseriadas. Vale ressaltar que, antes da aplicação do questionário aos alunos estudados, realizou-se a aplicação de um questionário piloto com discentes de outros anos (quinto ou sétimo ano), conforme recomendado por Hill e Hill (2008). Com isso, possíveis problemas que poderiam prejudicar o andamento da pesquisa, como linguagem inapropriada para a idade ou estrutura lógica, foram descartados (CHIZZOTI, 2010; SEVERINO, 2007).

Ademais, também foram realizadas entrevistas semiestruturadas com professores, com o objetivo de sondar a visão deles sobre a possibilidade de diferença de rendimento escolar entre alunos residentes nas áreas rural e urbana, bem como suas possíveis causas, dificuldades de ensino e estratégias para saná-las. Nesse caso, os interlocutores foram quatro professores do sexto ano: um que ministra aulas somente de Português, um que leciona apenas Matemática, um que ministra aulas de Português e Matemática e um que leciona somente Ciências. Estas entrevistas foram registradas com o auxílio de um gravador e, posteriormente, transcritas, textualizadas e analisadas.

\section{Resultados}

No total, o rendimento de 88 alunos da EMM foi analisado. Destes, 19,3\% vivem na área urbana $(\mathrm{N}=17)$, enquanto a maioria, $80,7 \%(\mathrm{~N}=71)$, é oriunda da área rural. De acordo com registros escolares, os alunos da área rural são provenientes de 23 localidades. $\mathrm{O}$ número de alunos do gênero masculino é semelhante ao do feminino, tanto na área urbana como na área rural (Figura 1). Os alunos pesquisados têm entre 11 e 17 anos, o que evidencia a distorção idade-série. 
Figura 1 - Distribuição dos alunos oriundos da cidade e da área rural na turma do sexto ano da escola analisada, segundo o gênero

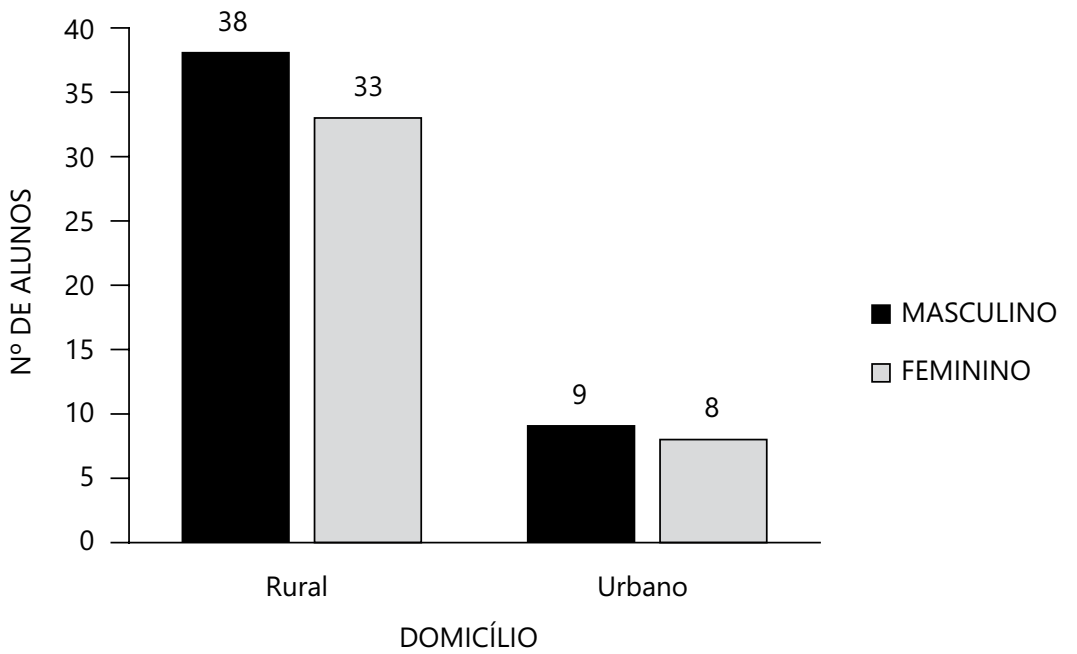

Fonte: Dados da pesquisa, 2017

Os alunos que moram na área urbana tiveram um rendimento melhor que os da área rural em todas as disciplinas analisadas (Tabela 1). A proporção de alunos que precisaram participar da recuperação semestral (pelo menos uma vez no ano) foi maior para o grupo da área rural (Figura 2). Tal fato se repetiu quando se observou o domicílio dos alunos reprovados, em que a proporção de alunos da área rural foi maior do que os da área urbana (Figura 3).

Tabela 1 - Média e desvio-padrão do rendimento escolar dos alunos nas turmas do sexto ano da escola analisada em diferentes disciplinas, considerando-se a localização do domicílio

\begin{tabular}{lccl}
\hline \multirow{2}{*}{ Domicílio } & \multicolumn{3}{c}{ Disciplina } \\
\cline { 2 - 4 } & Matemática & Português & Ciências \\
\hline Rural & $5,7 \pm 1,9$ & $5,9 \pm 1,9$ & $6,2 \pm 1,9$ \\
Urbano & $6,3 \pm 2,0$ & $6,9 \pm 1,8$ & $6,7 \pm 1,8$ \\
\hline
\end{tabular}

Fonte: Dados da pesquisa, 2017 
Figura 2 - Localização do domicílio dos alunos em recuperação semestral nas turmas do sexto ano da escola analisada

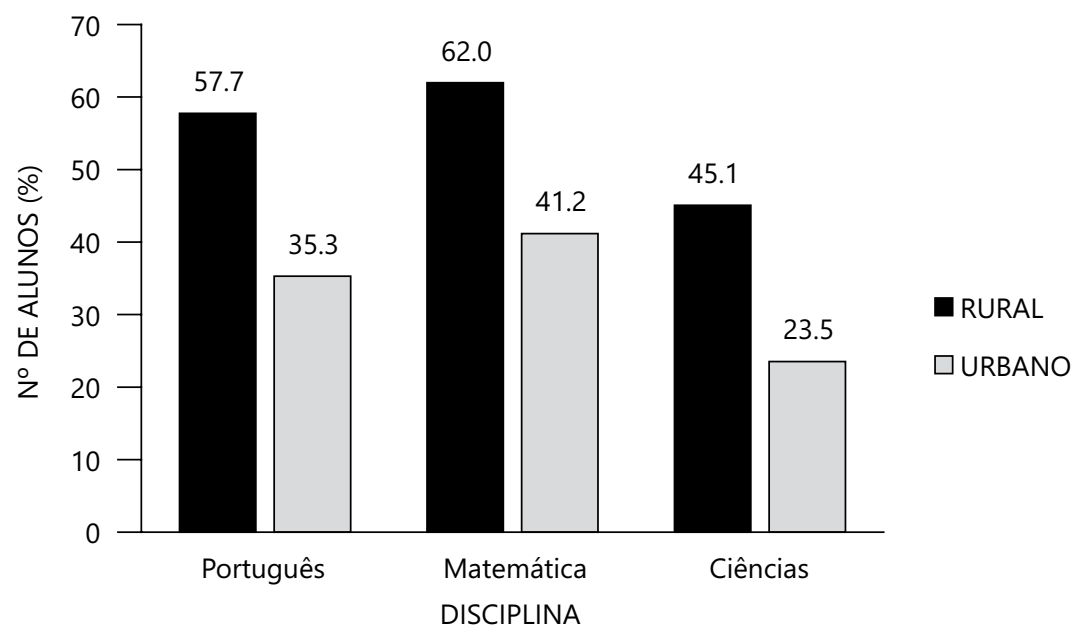

Fonte: Dados da pesquisa, 2017

Figura 3 - Localização do domicílio dos alunos reprovados nas turmas do sexto ano da escola analisada

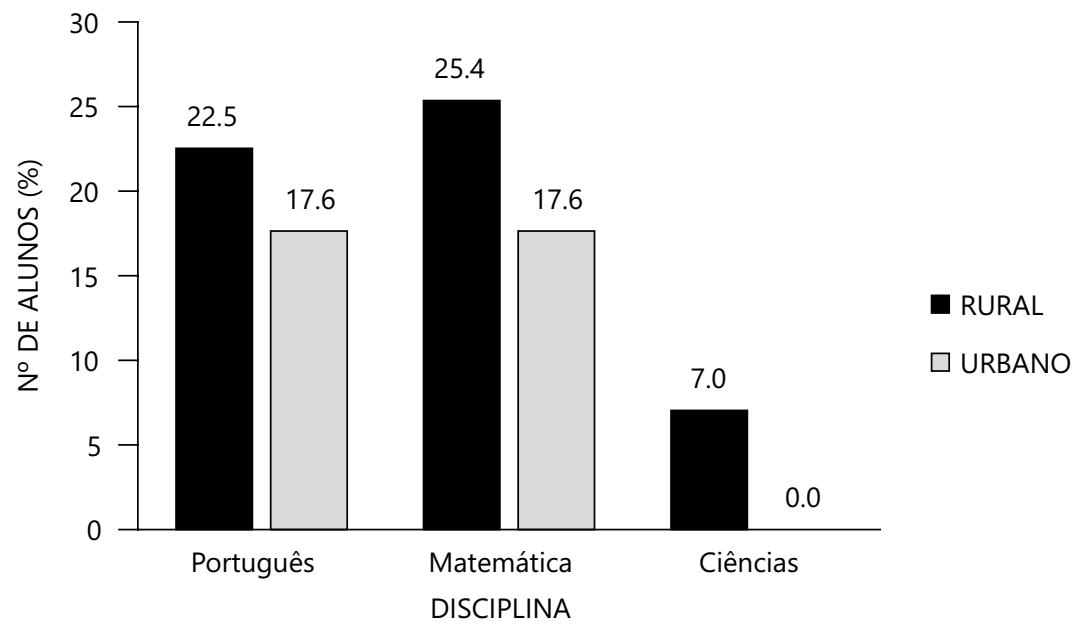

Fonte: Dados da pesquisa, 2017

Dessa forma, a partir dos dados apresentados anteriormente, constatou-se que há uma desigualdade no desempenho escolar entre alunos residentes nas áreas urbana e rural. Por conseguinte, procurou-se identificar os fatores influenciadores 
dessa desigualdade. Nesse sentido, o questionário respondido pelos alunos apontou uma série de aspectos sociais e escolares que podem influenciar, direta e indiretamente, no desenvolvimento da aprendizagem (Quadro 1). Entre os fatores sociais, destacam-se o número de moradores por domicílio, a escolaridade dos pais e a renda. Os aspectos escolares podem ser divididos em três níveis: a) do aluno, quando considera-se sua trajetória escolar, uso de transporte escolar e acompanhamento dos pais; b) da turma, quando relatam indisciplina e superlotação; c) da escola, quando consideram-se a ocorrência de aulas vagas e os problemas na estrutura física.

Quadro 1 - Aspectos sociais e escolares que podem influenciar, direta e indiretamente, na aprendizagem de alunos da área rural e/ou da área urbana nas turmas do sexto ano da escola analisada

\begin{tabular}{|c|c|c|}
\hline \multirow[t]{4}{*}{$\begin{array}{l}\text { Aspectos } \\
\text { sociais }\end{array}$} & \multirow[t]{4}{*}{$\begin{array}{l}\text { Nível do } \\
\text { aluno }\end{array}$} & $\begin{array}{l}\text { A média de pessoas que residem na mesma casa é maior } \\
\text { para os alunos que moram na área rural do que daqueles que } \\
\text { moram na área urbana ( } 5,1 \text { e } 4,3 \text {, respectivamente). }\end{array}$ \\
\hline & & $\begin{array}{l}\text { A maioria dos pais da área rural nunca estudou e as mães, } \\
\text { geralmente, não possuem o Ensino Fundamental completo. Os } \\
\text { pais da área urbana possuem escolaridade variada, enquanto } \\
\text { a maioria das mães conclúram o Ensino Médio ou já cursam o } \\
\text { Ensino Superior. }\end{array}$ \\
\hline & & $\begin{array}{l}\text { Enquanto as famílias da área urbana recebem, pelo menos, } \\
\text { um salário mínimo, a maioria das famílias rurais recebem } \\
\text { abaixo desse valor. }\end{array}$ \\
\hline & & $\begin{array}{l}\text { Dificuldade em se adaptar à convivência com os novos colegas } \\
\text { de sala (aluno da área rural). }\end{array}$ \\
\hline \multirow[t]{8}{*}{$\begin{array}{l}\text { Aspectos } \\
\text { escolares }\end{array}$} & \multirow[t]{4}{*}{$\begin{array}{l}\text { Nível do } \\
\text { aluno }\end{array}$} & $\begin{array}{c}\text { Tanto os alunos da área rural como da área urbana possuem } \\
\text { dificuldade de aprendizagem nas disciplinas de Português } \\
\text { e de Matemática. }\end{array}$ \\
\hline & & $\begin{array}{l}\text { A maioria dos alunos da área rural fez pelo menos a Educação } \\
\text { Infantil em salas multisseriadas. }\end{array}$ \\
\hline & & $\begin{array}{l}\text { Todos os alunos da área rural utilizam o transporte escolar, } \\
\text { cuja viagem varia entre } 20 \text { min e } 1 \mathrm{~h} \text {. }\end{array}$ \\
\hline & & $\begin{array}{l}\text { Todos os alunos da área urbana possuem ajuda dos pais nas } \\
\text { atividades escolares, nem que seja algumas vezes. A maioria } \\
\text { dos alunos da área rural também é acompanhada pelos pais, } \\
\text { mas alguns não recebem esse tipo de ajuda. }\end{array}$ \\
\hline & \multirow{2}{*}{$\begin{array}{l}\text { Nível de } \\
\text { turma }\end{array}$} & Indisciplina em sala de aula. \\
\hline & & Superlotação de turmas. \\
\hline & \multirow{2}{*}{$\begin{array}{l}\text { Nível de } \\
\text { escola }\end{array}$} & Existência de aulas vagas. \\
\hline & & $\begin{array}{l}\text { Salas sujas e desconfortáveis, principalmente quanto à } \\
\text { sensação térmica (alunos da área urbana). }\end{array}$ \\
\hline
\end{tabular}

Fonte: Dados da pesquisa, 2017 
Por meio da entrevista com os professores, foi possível obter outra série de variáveis contextuais que puderam ser relacionadas com a desigualdade do rendimento escolar entre os alunos residentes nas áreas urbana e rural. Os professores apontaram como possíveis causas dessa desigualdade: a escolaridade dos pais e, consequentemente, a dificuldade de acompanhamento das atividades escolares dos filhos; o ensino multisseriado nas escolas da área rural e a falta de acesso a alguns recursos educacionais, que seriam necessários para o desenvolvimento de atividades (uma das professoras relatou, inclusive, que tais recursos são mais acessíveis aos alunos da área urbana). Mesmo assim, alguns professores afirmam que os alunos da área rural possuem as mesmas capacidades e necessidades de aprendizagem que os oriundos da área urbana, por isso, não há distinção das atividades e das estratégias de ensino ofertadas a ambos os grupos. Por outro lado, há professores que se preocupam em trabalhar atividades diversificadas, de forma a contemplar tanto os alunos da área rural como os da área urbana, e auxiliam os que estão com dificuldade em aprender por meio de atividades extraclasse e revisão de conteúdos trabalhados, independentemente de sua área de domicílio. Entretanto, os professores apontaram a existência de mais um fator limitante para o desenvolvimento educacional dos alunos da área rural: o transporte escolar. Tal fato é explicitado quando um dos professores afirmou que, apesar da escola ser contemplada com programas educacionais, que funcionam no contraturno, a grande parcela do público atendido por esses programas é formada pelos alunos da área urbana, pois a inexistência de transporte no horário dessas atividades impossibilita a participação dos alunos da área rural.

\section{Discussão}

Com base nos dados apresentados, que relacionam as situações de domicílio dos alunos com os resultados das suas avaliações em Português, em Matemática e em Ciências, verificou-se que o rendimento dos alunos residentes na área rural é menor em relação ao dos alunos residentes na área urbana. Isso, por sua vez, é um indício que o aproveitamento do ensino e da aprendizagem dos alunos residentes da área rural foram menos satisfatórios.

Desse modo, a pesquisa corrobora algo já constatado quantitativamente em nível nacional: a desigualdade educacional entre os mundos urbano e rural do Brasil. Nesse sentido, Oliveira e Montenegro (2010, p. 78), comentaram, com base em dados do Censo Escolar 2006, do Instituto Nacional de Estudos e Pesquisas Educacionais Anísio Teixeira (Inep): "A avaliação do desempenho escolar realizada [...] revela diferenças no aprendizado dos alunos das áreas urbana $\mathrm{e}$ rural e, mais ainda, a persistente manutenção dessas desigualdades no tempo". Então, há evidências de desigualdade no desempenho entre alunos das áreas 
urbana e rural, não apenas em nível nacional, mas também localmente, conforme mostraram os dados da escola EMM. Percebe-se, ademais, que essa desigualdade continua "no tempo", mesmo depois que alunos residentes da área rural partem para a escola da área urbana, pois a formação escolar anterior é um fator que influencia o rendimento escolar (BONAMINO; OLIVEIRA, 2013; FONSECA; NAMEN, 2016). Dessa forma, pode-se inferir que as marcas do fracasso escolar que permeiam as escolas da área rural continuam sendo carregadas pelos alunos, mesmo quando esses migram para as escolas da área urbana.

Entretanto, não basta apenas aferir que há uma desigualdade entre o rendimento escolar de alunos residentes em diferentes situações de domicílio. A avaliação não pode ser apenas somativa, classificatória, o que poderia condenar escolas, professores e alunos à reprodução e à perpetuação dessa desigualdade (BLOOM; HASTINGS; MADAUS, 1983). É preciso, através da pesquisa educacional, que se compreenda as causas dessa desigualdade e que se tomem medidas para a sua superação (LUCKESI, 2008). Como concluíram Oliveira e Montenegro (2010, p. 79): "Conhecer as marcas das desigualdades do sistema escolar do campo é condição fundamental para se compreender os resultados obtidos nas escolas e, principalmente, para se construir os caminhos necessários à sua superação". Além disso, Oliveira e Montenegro (2010, p. 47) explicaram que

As díspares condições socioeconômicas, que permeiam os processos de aprendizagem dos sujeitos do campo, articulam-se com as desigualdades da renda auferidas pelo núcleo familiar, com desigualdades de acesso, de formação e de infraestrutura presentes no campo brasileiro.

Dessa forma, a compreensão da desigualdade do rendimento escolar entre alunos residentes na área rural e alunos residentes na área urbana exige também a compreensão do seu contexto socioeconômico. Por isso, através deste trabalho, foi investigada a relação entre o rendimento escolar dos alunos e os fatores econômicos e sociais próprios da sua realidade.

A partir dos dados coletados através das entrevistas com os professores e dos questionários aplicados aos alunos, foi possível tecer algumas inferências sobre fatores que podem estar relacionados à desigualdade no rendimento escolar entre alunos residentes na área rural e na área urbana:

a) A escolaridade e o acompanhamento dos pais dos alunos são diferentes entre aqueles que moram na área urbana e na área rural. Esses últimos têm 
menos escolaridade e acompanham com menos frequência os estudos dos filhos. Nesse caso, há indícios de que há uma relação entre a escolaridade e o acompanhamento dos pais, quando aqueles que possuem maior nível de escolaridade são mais propensos a acompanhar as atividades que os filhos levam para casa (nesse caso, os alunos que residem em área urbana). Esses pais podem sentir-se mais confiantes e/ou possuírem uma maior gama de conhecimentos que propiciem um acompanhamento "mais efetivo", analisando, identificando e realizando intervenções nos processos de desenvolvimento e aprendizagem dos filhos.

b) Apesar da renda da família não ser um fator diretamente ligado à escola, ela pode acabar interferindo negativamente na aprendizagem. $O$ fato de a família passar por dificuldades financeiras pode influenciar as relações pessoais em casa, acarretando problemas de ansiedade, estresse e tensão. Tais pontos podem afetar a aprendizagem, o aluno não terá um ambiente extraescolar saudável e propício para o desenvolvimento de suas habilidades e conhecimentos. Além disso, a renda menor pode limitar o acesso do aluno a alguns recursos educacionais e culturais, como a internet, os livros e as viagens.

c) Todos os alunos da área rural precisam deslocar-se para a escola na área urbana. Isso representa não somente um risco para os estudantes, mas também uma experiência mais cansativa e desestimulante. A situação agrava-se quando se considera que os veículos utilizados para esse transporte podem não estar em boas condições de uso, aumentando o risco para os estudantes. Esses alunos acabam tendo menos tempo de estudo extraclasse, pois passam um grande tempo deslocando-se de casa para escola, e vice-versa, e precisam adaptar-se aos horários preestabelecidos do transporte, o que acaba limitando a participação dos alunos da área rural em atividades extracurriculares e de reforço.

d) A formação escolar anterior do aluno é um fator chave e deve ser considerada pelo professor. Tal compromisso é essencial para análise de rendimento se considerarmos dois fatos: (i) na maioria das vezes, o que chamamos de rendimento é resultado somente da avaliação realizada em sala de aula e que possui caráter classificatório, discriminativo e seletivo; e (ii) muitas vezes, o professor traça objetivos de aprendizagem contando que o aluno possui certos conhecimentos obtidos em etapas escolares anteriores, porém, nem sempre isso acontece, o que dificulta a aprendizagem e, consequentemente, o desempenho em avaliações (SOUSA, 1991). Alguns alunos oriundos da área rural estudaram em turmas multisseriadas em escolas anteriores, dividindo a mesma sala e o mesmo professor com outros discentes de anos 
escolares distintos. De acordo com Oliveira e Montenegro (2010, p. 74), "essa adaptação pedagógica [...] nos últimos anos veio sendo considerada uma alternativa inadequada, vinculada à baixa qualidade do ensino". Entre os diversos fatores que comprometem o ensino em turmas multisseriadas está a falta de capacitação de professores para trabalharem com esse tipo de organização pedagógica (HAGE, 2011; OLIVEIRA; MONTENEGRO, 2010). De acordo com Hage (2011, p. 100), os professores de turmas multisseriadas não possuem uma formação voltada para trabalharem "com a heterogeneidade de idades, séries e ritmos de aprendizagem, entre outras que se manifestam com muita intensidade nessas escolas ou turmas". Além disso, os docentes "organizam o seu trabalho pedagógico sob a lógica da seriação, desenvolvendo suas atividades educativas referenciados por uma visão de 'ajuntamento' de várias séries ao mesmo tempo" (HAGE, 2011, p. 100). Sendo assim, os alunos que estudaram em turmas multisseriadas podem não possuir conhecimentos pré-estabelecidos devido a um "ensino multisseriado de baixa qualidade", comprometendo o seu rendimento em anos escolares posteriores.

Dessa forma, a pesquisa mostrou que há vários fatores que podem estar relacionados com a desigualdade do rendimento escolar entre alunos residentes em situações de domicílio diferentes, como (a) a escolaridade e o acompanhamento dos pais, (b) a renda da família, (c) a distância escola-residência e (d) a formação escolar anterior dos alunos. As relações apontadas pelos itens (a), (b) e (c) também foram estudadas por Bacha et al. (2006), ao apontar diversas pesquisas que as ratificam.

O mesmo dá-se com Rodrigues (2017, p. 40) que, ao tratar do menor desempenho de alunos residentes na área rural, relacionou:

Quando a comparação é feita em relação ao Status Econômico Familiar (SEF), percebe-se que, em média, as crianças que estudam em escolas urbanas vivem em domicílios com melhores condições do que aquelas que estudam no meio rural. Além disso, a escolaridade dos pais também é pior entre os alunos no meio rural; ou seja, as crianças rurais apresentam condições socioeconômicas desfavoráveis em relação às que estudam em escolas urbanas, tanto do ponto de vista de bens no domicílio, conforme o SEF, como sob o prisma de capital humano disponível no lar.

Destarte, isso confirma a inferência sobre a relação entre a formação e o acompanhamento escolar feito pelos pais e a renda da família com o rendimento escolar dos alunos residentes na área rural. 
Ademais, o peso de se morar distante da escola, algo intensificado por processos de nucleação e de fechamento de escolas, salientado no item (c), também foi ressaltado por Silva e Kichow (2013). Estes autores evidenciaram os desgastes provocados pelo trabalho no campo e pela distância residência-escola a ser ultrapassada, além das condições precárias das estradas rurais e do transporte escolar, muitas vezes sem a segurança adequada.

Os resultados oriundos desta pesquisa trazem o diferencial de apontar a formação escolar anterior dos alunos como um fator influenciador da desigualdade de rendimento escolar em relação à situação de domicílio, pois os interlocutores da pesquisa apontaram o multisserialismo escolar como uma das causas para um menor desempenho dos alunos da área rural em relação àqueles que moram na área urbana.

Outrossim, a pesquisa aponta a necessidade de estudos de larga escala que relacionem os resultados do rendimento escolar a fatores contextuais e socioeconômicos influenciadores nas escolas do campo na Região Nordeste do Brasil, para, dessa forma, constatar-se a amplitude do problema. Estudos como esses podem avaliar e problematizar se pouco mudou no cenário educacional nordestino de escolas situadas na área rural desde as avaliações realizadas na década de 1980 pelo Programa de Expansão e Melhoria do Ensino no Meio Rural do Nordeste Brasileiro (Edurural). Naquela época, o baixo rendimento escolar de diversas escolas rurais de alguns estados do Nordeste, dentre os quais o Piauí, foi relacionado ao ensino multisseriado precário, às condições das escolas, ao perfil e às condições de trabalho e ao impacto do treinamento dos professores e das condições familiares (VIANNA, 1995).

É preciso que se compreenda a desigualdade do rendimento escolar entre o rural e o urbano, a partir do conhecimento, não apenas dos índices, mas também da realidade contextual desses diferentes espaços. Além disso, é também preciso que se problematize essa desigualdade para pensarmos uma Educação no meio rural que não seja inferior àquela que ocorre no meio urbano. Esse tipo de problematização é o que tem catalisado, desde os fins da década de 1990, o movimento nacional por uma Educação do Campo, isto é, uma Educação pensada a partir e para as classes trabalhadoras do campo, inserida em um projeto maior, de desenvolvimento nacional e que assuma a complementariedade entre o rural e o urbano (CALDART, 2012; KOLLING; NERY; MOLINA, 1999).

\section{Conclusões}

Dentre as conclusões que se pode chegar, a partir dos dados apresentados e discutidos neste trabalho, está a asserção de que existe uma desigualdade entre o 
rendimento de alunos que moram na área rural e na área urbana. Tal desigualdade pode estar relacionada à escolaridade dos pais e, consequentemente, à dificuldade de acompanhamento das atividades escolares dos filhos; a renda da família; o ensino multisseriado nas escolas da área rural e a distância escola-residência.

Por conseguinte, a pesquisa mostra que o problema da desigualdade rural-urbano, concernente ao rendimento escolar, situa-se não apenas na comparação entre as escolas localizadas na área urbana versus as situadas na área rural: a desigualdade também está presente nas escolas localizadas na área urbana que recebem alunos oriundos do campo e da cidade, ampliando a extensão do problema do rendimento escolar em relação à situação de domicílio, não sendo somente um comparativo onde a escola está, mas considerando também a origem do corpo discente que a compõe. Portanto, a pesquisa mostra a importância de se ampliar o foco da pesquisa educacional sobre a desigualdade rural-urbano através de estudos em escolas urbanas que atendem alunos residentes da área rural.

Além disso, através deste trabalho, é possível perceber mais um sinal de que os estudos sobre a Educação do Campo não tratam apenas do campo, mas tangem toda a sociedade. Mostra-se que o rendimento escolar de alunos residentes no campo e, consequentemente, os processos educativos relacionados com a sua aferição, que remontam ao planejamento, à execução e às diversas formas de avaliação realizadas dos alunos, de turmas e de escola, impactam sobre a escola como um todo, sendo esta uma escola urbana. Isso acontece porque campo e cidade estão organicamente ligados, fazendo parte de uma mesma sociedade. Dessa maneira, os problemas educacionais, que tangem a população do campo, influenciam a sociedade como um todo, tanto o rural como o urbano. Por isso, a caracterização, a compreensão e as ações capazes de desencadear mudanças quanto à desigualdade educacional entre campo e cidade são do interesse de toda a sociedade, já que são para o bem de todos. 


\section{School performance: a comparative study between rural and urban students in a public school of Piauí}

\section{Abstract}

The aim of this study was to compare the school performance between rural and urban students of 6th-grade in a public school of Piaui. Furthermore, the socioeconomic and school factors that influence performance were investigated, according to teachers and students. Performance data were obtained from school records, and the performance-influencing factors were investigated through questionnaires and interviews. School records showed that students living in the rural area had lower performance compared to those living in the urban area. This variation would be related to social and school aspects in different levels: student, class and school.

Keywords: School Evaluation. Rural-urban. Influencing factors.

\section{Rendimiento escolar: un estudio comparativo entre estudiantes del área urbana y el área rural en una escuela pública en Piauí}

\section{Resumen}

El objetivo principal de este estudio fue comparar el rendimiento escolar entre los estudiantes de sexto grado que viven en el área urbana y en el área rural de una escuela pública en Piauí. Además, se investigaron las causas socioeconómicas y escolares que influyen en dicho desempeño, de acuerdo con maestros y estudiantes. Los datos de rendimiento se obtuvieron a través de los registros escolares, y los factores que influyen en el rendimiento se investigaron a través de cuestionarios y entrevistas. Los registros escolares mostraron que los estudiantes que viven en áreas rurales tienen ingresos más bajos en comparación con aquellos que viven en áreas urbanas. Esta variación estaría relacionada con aspectos sociales y escolares en diferentes niveles: estudiante, clase y escuela.

Palabras clave: Evaluación Escolar. Rural-urbano. Factores Influyentes. 


\section{Referências}

ALVES, M. T. G.; SOARES, J. F.; XAVIER, F. P. Índice socioeconômico das escolas de educação básica brasileiras. Ensaio: Avaliação e Políticas Públicas em Educação, Rio de Janeiro, v. 22, n. 84, p. 671-704, jul./set. 2014. https://doi.org/10.1590/S0104-40362014000300005

AMÉRICO, B. L.; LACRUZ, A. J. Contexto e desempenho escolar: análise das notas na Prova Brasil das escolas capixabas por meio de regressão linear múltipla. Revista de Administração Pública, Rio de Janeiro, v. 51, n. 5, p. 854-878, set./out. 2017. https://doi.org/10.1590/0034-7612160483

BACHA, S. M. C. et al. Rendimento escolar de alunos da área rural em escola urbana. Revista CEFAC, São Paulo, v. 8, n. 4, p. 429-440, out./dez. 2006. https://doi.org/10.1590/S1516-18462006000400004

BLOOM, B.; HASTINGS, T.; MADAUS, G. Manual de avaliação formativa e somativa do aprendizado escolar. São Paulo: Pioneira, 1983.

BONAMINO, A.; OLIVEIRA, L. H. G. Estudos longitudinais e pesquisa na educação básica. Linhas Críticas, Brasília, DF, v. 19, n. 38, p. 33-50, jan./abr. 2013. https://doi.org/10.26512/lc.v19i38.4084

BRASIL. Senado Federal. Constituição da República Federativa do Brasil de 1988. Diário Oficial da União, Brasília, DF, 5 out. 1988.

BRASIL. Ministério de Educação e Cultura. Lei No 9.394, de 20 de dezembro de 1996. Estabelece as diretrizes e bases da educação nacional. Diário Oficial da União, Brasília, DF, 20 dez. 1996.

CALDART, R. S. Educação do campo. In: CALDART, R. S. et al. (org.).

Dicionário da educação do campo. 2. ed. Rio de Janeiro/São Paulo: Escola

Politécnica de Saúde Joaquim Venâncio, Expressão Popular, 2012. p. 257-265.

CHIZZOTTI, A. Pesquisa qualitativa em ciências humanas e sociais. 11. ed. São Paulo: Cortez, 2010.

COLEMAN, J. S. Desempenho nas escolas públicas. In: BROOKE, N.; SOARES, J. F. Pesquisa em eficácia escolar: origem e trajetórias. Belo Horizonte: Editora UFMG, 2008. p. 26-32.

COLEMAN, J. S. et al. Equality of educational opportunity. Washington, DC: National Government Printing Office, 1966. 
COSTA, G. D. F. Relações entre as orientações motivacionais e o desempenho escolar de alunos da $7^{a}$ série do Ensino Fundamental em Matemática, na resolução de equações do $1^{\circ}$ grau. Dissertação (Mestrado em Educação) - Faculdade de Educação, Universidade Estadual de Campinas, Campinas, 2005.

DAL-FARRA, R. A.; LOPES, P. T. C. Métodos mistos de pesquisa em educação: pressupostos teóricos. Nuances: Estudos sobre Educação, Presidente Prudente, v. 24, n. 3, p. 67-80, 2013. https://doi.org/10.14572/nuances.v24i3.2698

FARIA, E. M.; GUIMARÃES, R. R. M. Excelência com equidade: fatores escolares para o sucesso educacional em circunstâncias desfavoráveis. Estudos em Avaliação Educacional, São Paulo, v. 26, n. 61, p. 192-215, jan./abr. 2015. https://doi.org/10.18222/eae266103115

FONSECA, E. O.; NAMEN, A. A. Mineração em bases de dados do Inep: uma análise exploratória para nortear melhorias no sistema educacional brasileiro. Educação em Revista, Belo Horizonte, v. 32, n. 1, p. 133-157, jan./mar. 2016. https://doi.org/10.1590/0102-4698140742

FUNDAÇÃO LEMANN. QEdu. Matrículas e Infraestrutura. [s.1.], 2016. Disponível em: http://www.qedu.org.br/brasil/censo-escolar?year=2013\&depe ndence $=0 \&$ localization $=0 \&$ item $=$. Acesso em: 6 out. 2017 .

HAGE, S. M. Por uma escola do campo de qualidade social: transgredindo o paradigma (multi)seriado de ensino. Em aberto, Brasília, DF, v. 24, n. 85, p. $97-113$, abr. 2011. https://doi.org/10.24109/2176-6673.emaberto.24i85.\%25p

HAYDT, R. C. Avaliação do processo ensino-aprendizagem. 6. ed. São Paulo: Ática, 1997.

HILL, M. M.; HILL, A. Investigação por questionário. 2. ed. Lisboa: Sílabo, 2008.

INSTITUTO BRASILEIRO DE GEOGRAFIA E ESTATÍSTICA - IBGE. Censo demográfico 2010: resultados preliminares do universo: conceitos e definições: tabelas adicionais. Rio de Janeiro: Ministério do Planejamento, Orçamento e Gestão, 2011.

KOLLING, E. J.; NERY, I.; MOLINA, M. C. Por uma educação básica do campo. Brasília, DF: Articulação Nacional por uma Educação do Campo, 1999. (Coleção Por uma Educação Básica do Campo, 1). 
LUCKESI, C. C. Avaliação da aprendizagem escolar: estudos e proposições. 19. ed. São Paulo: Cortez, 2008.

MASCARENHAS, S. Atribuições causais e rendimento no ensino médio. Rio de Janeiro: Ed. Autora, 2004.

OLIVEIRA, L. L. N. A.; MONTENEGRO, J. L. A. Panorama da educação do campo. In: MUNARIM, A. et al. (org.). Educação do campo: reflexões e perspectivas. Florianópolis: Insular, 2010. p. 47-80.

OSTI, A.; MARTINELLI, S. C. Desempenho escolar: análise comparativa em função do sexo e percepção dos estudantes.

Educação e Pesquisa, São Paulo, v. 40, n. 1, p. 49-59, jan./mar. 2014. https://doi.org/10.1590/S1517-97022013005000021

PALERMO, G. A.; SIVIA, D. B. N.; NOVELLINO, M. S. F. Fatores associados ao desempenho escolar: uma análise da proficiência em matemática dos alunos do $5^{\circ}$ ano do ensino fundamental da rede municipal do Rio de Janeiro. Revista Brasileira de Estudos de População, Rio de Janeiro, v. 31, n. 2, p. 367-394, jul./ dez. 2014. https://doi.org/10.1590/S0102-30982014000200007

PARREIRA, A.; SILVA, A. L. A lógica complexa da avaliação. Ensaio: Avaliação e Políticas Públicas em Educação, Rio de Janeiro, v. 23, n. 87, p. 367-388, abr./jun. 2015. https://doi.org/10.1590/S0104-40362015000100015

RODRIGUES, L. O. Ensaios sobre o diferencial de desempenho escolar entre alunos de escolas rurais e urbanas no Brasil. Dissertação (Mestrado em Economia Rural) - Centro de Ciências Agrárias, Universidade Federal do Ceará, Fortaleza, Ceará, 2017.

SEVERINO, A. J. Metodologia do trabalho científico. 23. ed. São Paulo: Cortez, 2007.

SILVA, G. C. R. F. Atribuições causais sobre o rendimento escolar dos estudantes do $9^{\circ}$ ano do Ensino Fundamental de Manaus. Dissertação (Mestrado em Psicologia) - Faculdade de Psicologia, Universidade Federal do Amazonas, Manaus, Amazonas, 2011.

SILVA, C. B.; KICHOW, I. V. A transição da escola rural para a escola urbana e seus reflexos no Ensino de Matemática: um caso na cidade de Laguna Carapã. In: ENCONTRO NACIONAL DE EDUCAÇÃO MATEMÁTICA, 11., 2013, Curitiba. Anais [...] Curitiba: Sociedade Brasileira de Educação Matemática, 2013. p. 1-7. 
SOARES, J. F.; ANDRADE, R. J. Nível socioeconômico, qualidade e eqüidade das escolas de Belo Horizonte. Ensaio: Avaliação e Políticas Públicas em Educação, Rio de Janeiro, v. 14, n. 50, p. 107-126, jan./mar. 2006. http:s//doi.org/10.1590/S0104-40362006000100008

SOUSA, C. P. Avaliação do rendimento escolar: sedimentação de significados. In: SOUSA, C. P. (org.). Avaliação do rendimento escolar. Campinas, SP: Papirus, 1991. p. 143-150.

VIANNA, H. M. Avaliação educacional: uma perspectiva história. Estudos em Avaliação Educacional, São Paulo, n. 12, p. 7-24, 1995. https://doi.org/10.18222/eae01219952297

VILELA-RIBEIRO, E. B.; BENITE, A. M. C. A escola como espelho da sociedade: o desempenho escolar em ciências é afetado pela escola que os estudantes frequentam? Meta: Avaliação, Rio de Janeiro, v. 7, n. 21, p. 364-381, set./dez. 2015. https://doi.org/10.22347/2175-2753v7i21.835

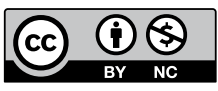

\section{Informações dos autores}

Suzana Gomes Lopes: Doutora em Biotecnologia pela Rede Nordeste de Biotecnologiaponto focal Universidade Federal do Maranhão. Docente do Curso de Licenciatura em Educação do Campo/Ciências da Natureza da Universidade Federal do Piauí. Contato: sglopes@ufpi.edu.br

(iD) https://orcid.org/0000-0001-9071-9585

Isabel Matilde de Carvalho Xavier: Graduada em Educação do Campo/Ciências da Natureza pela Universidade Federal do Piauí. Contato: isabelmcxavier@hotmail.com

(iD) https://orcid.org/0000-0002-1063-6040

Alexandre Leite dos Santos Silva: Doutor em Educação pela Universidade Federal de Uberlândia. Docente do Curso de Licenciatura em Educação do Campo/Ciências da Natureza da Universidade Federal do Piauí. Contato: alexandreleite@ufpi.edu.br

(iD) https://orcid.org/0000-0002-8239-9240 